\title{
RISK MANAGEMENT IMPLEMENTATION FOR SUSTAINABLE DEVELOPMENT OF ROMANIAN SMES: A FUZZY APPROACH
}

\author{
Carmen Nadia Ciocoiu ${ }^{1}$, Adina Liliana Prioteasa ${ }^{2 *}$ and Sofia Elena Colesca ${ }^{3}$ \\ ${ }^{122) 3)}$ The Bucharest University of Economic Studies, Romania
}

\section{Please cite this article as:}

Ciocoiu, C.N., Prioteasa, A.L. and Colesca, S.E., 2020.

Risk Management Implementation for Sustainable Development of Romanian SMEs: A Fuzzy Approach.

Amfiteatru Economic, 22(55), pp. 726-741.

\section{Article History}

Received: 30 March 2020

Revised: 20 May 2020

Accepted: 3 June 2020

\section{DOI: $10.24818 / \mathrm{EA} / 2020 / 55 / 726$}

\begin{abstract}
Small and medium-sized enterprises (SMEs) are recognized for their major contribution to the economic development of any country. In Romania, SMEs represent $99.7 \%$ of all organizations and employ approximately $66 \%$ of all nationally registered employees, percentages approximately equal to those recorded in the European Union. However, the productivity of Romanian SMEs is quite low, feeling very strong any influence from the external environment. Risk management is increasingly considered a tool that can contribute to the sustainable development of SMEs. The implementation of a risk management system is a complex process, influenced by many factors. In this context, the objective of the present article is to analyze the determinants of behavior towards the implementation of risk management in Romanian SMEs. The data for the analysis were obtained through a questionnaire addressed to SMEs and processed by a fuzzy model. The results revealed two essential ideas: (1) the determinants of SMEs behavior towards risk management implementation are: stakeholders' requirements, training in risk management, the existence of a leader for the implementation and attitude towards risk; (2) attitude toward risk is influenced by the business lifespan and awareness of the importance of risk management.
\end{abstract}

Keywords: small and medium-sized enterprises, integrated risk management, fuzzy approach, attitude towards risk, behavior, sustainable development

JEL Classification: C02, D81, L21, M10

* Corresponding author, Adina Liliana Prioteasa - prioteasaadina@ gmail.com 


\section{Introduction}

Decision-makers from the business environment started to agree, more and more, the fact that "integrated risk management" (IRM) is a viable way to strengthen the risk surveillance at organizational level, but also to ensure the sustainable development of each organizational entity. This type of integrated risk approach is referred in English literature as "enterprise risk management" (ERM) or "integrated risk management" (IRM). The implementation of IRM at business level is a proactive, continuous process which imply the adoption of a holistic approach to risks that may positively or negatively affect the achievement of organizational objectives, in this way contributing to the development of a robust and flexible business model (Institution of Civil Engineers and the Faculty and Institute of Actuaries, 2009 , p.13). On the other hand, IRM is one of the basic pillars of strategic management, being used to develop strategies to achieve competitive advantage. An increasingly competitive environment can create considerable problems for many organizations, even if they strive to adapt to changes and search new ways of thinking and making decisions (Brătianu, 2015). SMEs are structurally weaker and more likely to fail when faced with unexpected risks. As a result, many SMEs fail to create strong frameworks for their sustainable development.

Organizational sustainability has concerned academic literature over the past 25 years (Gladwin, et al., 1995; Bebbington and Gray, 1996; Hoffman and Ehrenfeld, 1998; Dyllick and Hockerts, 2002 cited in Yilmaz and Flouris, 2010; Mikhaylova, et al., 2019). These approaches were focused on various aspects relating to the contextual integration of economic, environmental and social factors. Sustainable development, from the business point of view, involves adopting strategies and carrying out activities that meet the organizational and stakeholders needs, protecting, supporting and increasing the human capital and the natural resources of the organization (WBCSD, 2016). Sustainability risk is perceived as an uncertain social event or environmental condition which, if it occurs, can cause a significant negative impact at organizational level (WBCSD, 2016).

UNEP Finance Initiative (2006) includes risk management (RM) between the four drivers for the implementation of sustainable management in emerging economies, the other being: increased revenues, capital access, and cost economies. Sustainability risk commitment requires a holistic and systematic integration of environmental, socio-economic and corporate risk factors into business management (Yilmaz and Flouris, 2010; Retkoceri and Kurteshi, 2019).

The research on the factors that influence the implementation of risk management (RM) in SMEs is still a very recent topic, even though the literature recognizes the broad importance of SMEs from economic and social perspectives (Verbano and Venturini, 2013; Marinescu, Constantin and Toma, 2016; Fedorov and Mikhaylov, 2019). The benefits of RM implementation are considered vital for the sustainable development of SMEs. These include, among others, the correct recording of commercial transactions, the timely generation of financial statements, the development of cordial relations with regulatory organizations, the timely identification of commercial and financial risks and management arrangements, the opportunity to manage uncertainty in advance by planning risk responses and reducing waste of resources (Vadiveloo, et al., 2015; Agrawal, 2016).

Although there are many papers that recognize the importance of RM for the sustainable development of SMEs, few of these are carried out for Romania, and the existing one's deal with the RM practices, without analyzing the factors influencing implementation. In this context, the first part of the article presents the stage of the research in the field, the analysis highlighting the main determinants of the behavior of SMEs towards RM implementation. 
The second part presents the research methodology, a fuzzy statistical method, fed with data obtained from a survey based on a questionnaire. The third part presents the results of the study. The last part of the article presents discussions on the basis of which the conclusions of the study are formulated.

\section{The stage of research on the implementation of risk management in SMEs}

The review of the literature shows that the implementation of RM in SMEs is a topic that arouses the interest of researchers and practitioners in all fields of activity. Nowadays, even there are many standards and guidelines dealing with the application of RM in SMEs, few of these analyze the attitude and behavior towards the implementation of RM. Risk awareness is quite low among SME owners and managers, with risk management actions being focused on safety, security, and health and quality assurance issues. "Loss control" programs are overseen by either the entrepreneur or another person of the management team and inappropriate time allocation for RM increases the chance of practicing a non-performing managerial act (Ntlhane, 1995).

Unlike large companies, RM in SMEs is frequently carried out by owners - managers. The extent and quality of RM in SMEs depend on the time invested by business owners in developing and implementing a risk strategy and how it is communicated to employees (Mudiyanselage and Jayathilake, 2012). The integration of RM into SMEs requires that management be focused on uncertainty recognition, continuous risk identification and the development of risk management plans. Within the IRM approach, as specified by the COSO (2004) framework, the RM process is integrated, and the risks can be both negative and positive. This type of approach can also be found in ISO 31000 (2018), considered the most important standard that provides guidance on the implementation and application of RM in any type of organization.

As regards the factors influencing the implementation of RM, they can be grouped into several categories, namely: characteristics of SMEs (Beasley, Clune and Hermanson, 2005; Hoyt and Liebenberg, 2011; Rostami, et al., 2015; Zhao and Singhaputtangkul, 2016), organizational culture (Fraser and Simkins, 2016), knowledge of the RM system (Dornberger, Oberlehner and Zadrazil, 2014) and external factors (Kleffner, Lee and McGannon, 2003; Gates, 2006).

The characteristics of SMEs are most often represented by their size, type of business and business lifespan. The type of business, often associated with a different degree of uncertainty depending on the field of activity, is a critical factor that strongly affects the implementation of RM systems. The results of the study conducted by Yaraghi and Langhe (2011) on 250 companies in Sweden confirm the common belief that organizations with a higher level of uncertainty in their production system will be more attracted to implement a RM system. The study is interesting in that it analyzes the success factors in three phases of RM implementation. In the first phase, the factors that influence the company's preparation for implementation are ranked, the top of these factors being held by the clearly defined strategy, team spirit, responsibility and business type. In both second phase (the design and implementation of the RM system) and third phase (system administration), the influence of the type of business on the success of the RM system is decreased. The results also demonstrate that the high level of competition and the complexity of the environment in which the organization operates play an important role in the decision on implementation of a RM system, an aspect also found by Dornberger, Oberlehner and Zadrazil (2014). 
The importance of the organization's dimension to the success of RM implementation is highlighted in the studies of authors Beasley, Clune and Hermanson (2005), Hoyt and Liebenberg (2011), Zhao and Singhaputtangkul (2016), but also in COSO (2004). The mentioned research show that the success of RM implementation is positively correlated with the size of the organization. On the other hand, the business lifespan can positively and negatively influence the implementation process.

An organizational culture focused on RM is an essential component for the implementation of this type of management at organizational level (Hillson and Murray-Webster, 2006; Fraser and Simkins, 2016). Within SMEs, the lack of adequate RM capacity leads to various types of risk culture. Risk culture is represented by the norms and behavioral traditions of individuals and groups belonging to an organization, with consequences on how the organization faces to various threats.

Fraser and Simkins (2016) identify both internal and external implementation challenges, including some misconceptions about RM. In their view, the internal obstacles for the success of RM implementation are represented by: corporate culture; knowledge of RM; carrying out, without prior preparation, trainings in the field of RM; creating a too extensive list of risks that can hinder the RM process; the extent to which RM is transformed into a pleasant activity for those who are involved in specific RM actions. Among the challenges mentioned, the one strongly supported by the authors refers to the organizational culture, they showing that the success of an integrated RM approach is directly proportional to transparency and teamwork. The need to create a risk-responsive culture within the organization is also supported in the study of Dornberger, Oberlehner and Zadrazil (2014).

Another factor that contributes to the formation of a culture of risk and has an important contribution for the implementation of RM is the knowledge and understanding, by the employees of the RM system (Vasile and Croitoru, 2012). Dornberger, Oberlehner and Zadrazil (2014) consider that an organization is ready to implement RM when it can educate its employees in this field. The main objective of an RM education and training program is not only to ensure that members of the organization are comfortable with the new RM system, but also to increase their expertise and knowledge.

Numerous studies address the issue of the factors that influence the success of RM implementation in construction companies. The main argument is that they carry out their activities in the form of projects that have a high degree of risk. For example, Rostami, et al. (2015) conducted a detailed analysis of the literature on RM in construction between 1991 and 2014, and discovered that the challenges of implementing RM at organizational level relate essentially to the people involved, the characteristics of the organization and the RM process. According to ISO (2018), the process the application of RM at advanced level contains a series of steps to be taken: setting the context, identifying, analyzing and assessing risks, treating, monitoring and reviewing them and communicating and consulting.

Agyakwa-Baah and Chileshen (2010) show that the first place among the factors that condition RM implementation is "management style", followed by "awareness of the risk management process", and "communication and teamwork". Another important factor is the knowledge in the field of RM, which can be obtained through participation in project management training programs. Training can prove its effectiveness by raising awareness of the use of RM procedures and delivering the necessary expertise in the use of RM processes.

A number of studies have also examined the role of the awareness of RM in shaping a proactive attitude towards the implementation of RM. Agyakwa-Baah and Chileshen (2010) have noted that the lack of awareness of the importance of RM can, inherently, lead to poor 
resource management. This fact is closely correlated with the critical success factors regarding the effective use of RM methods and tools. Raising awareness and understanding of employees regarding RM was identified by Mazlina and Amirah (2015) as an important factor influencing the implementation of RM in a company operating in the construction industry. Along with RM training, the need for a responsible person to implement and apply this type of management at organizational level is also mentioned (Dornberger, Oberlehner and Zadrazil, 2014; Fraser and Simkins, 2016). Based on previous research, Rostami, et al. (2015) found that the experience, knowledge and behavior of key actors is a barrier to the implementation of RM and, as a result, a small number of construction organizations have formal RM systems.

The attitude towards risk has been analyzed in a study conducted by the Economist Intelligence Unit (EIU, 2007), which interviewed managers around the world about their approach to RM and the main challenges and opportunities related to this type of management. To the question regarding the most important factor that contributes to the success of RM at the organizational level, managers placed a strong culture and risk awareness first, followed by a clearly defined risk attitude (EIU, 2007). Regarding the attitude towards risk, Fraser and Simkins (2016) states that the COSO (2004) guide on RM created mass confusion by popularizing the concepts of "appetite" and "risk tolerance", considered as inhibitors for the successful implementation of RM. The correction was carried out by ISO in 2009, by including the term "risk attitude" in the ISO 31000:2009 standard (replaced by ISO 31000:2018).

The most relevant external factors influencing the implementation of RM in SMEs are RM regulations and stakeholder requirements for the implementation of such a system. Kleffner, Lee and McGannon (2003) and Gates (2006) found in their studies that legal or regulatory pressure spurred the adoption of RM in firms in various industries. Zhao and Singhaputtangkul (2016) demonstrate that, in the case of Singapore construction firms, increased regulations are positively correlated with management involvement in the implementation of RM. Regarding the Romanian situation, a study conducted in 2015 revealed that the main external factors influencing the implementation of RM are: "increased concern on the part of RM regulators", "external organizational environment", "stakeholder pressure" and "type of business". In the group of internal factors, the most important is "topmanagement commitment", followed by "availability of resources", "competence and training in the field of RM", "risk culture" and "perceived usefulness in the field of RM" (Ciocoiu, 2015).

\section{Research methodology}

In order to test which are the main determinants of RM implementation in Romanian SMEs, we designed the model presented in Figure no. 1. The proposed model analyzes the impact of four categories of determinants on the attitude and behavior towards the implementation of the RM in the SMEs, respectively: the characteristics of SMEs, the organizational culture, the knowledge regarding the RM and the external factors (Figure no. 1 and Table no. 1). Also, a clearly attitude towards risk is considered an important factor that influences the SME behavior towards RM implementation. Table no. 1 presents the main determinants associated with the implementation of RM identified in the literature review. Based on these determinants, 12 research hypotheses were defined:

$H_{1}$ : There is a relationship between SME size and the attitude towards risk.

$\mathrm{H}_{2}$ : There is a relationship between the business lifespan and the attitude towards risk. 
$H_{3}:$ There is a relationship between the type of business in which the SME operates and the attitude towards risk.

$H_{4}:$ There is a relationship between risk attitude and behavior towards the implementation of $R M$.

$H_{5}$ : There is a relationship between promoting collaboration and communication between departments and the attitude towards risk.

$H_{6}:$ There is a relationship between understanding and awareness of the importance of RM and the attitude towards risk.

$H_{7}$ : There is a relationship between the existence of a leader for the implementation process and the behavior towards the implementation of RM.

$H_{8}$ : There is a relationship between the level of management involvement and the attitude towards risk.

$H_{9}:$ There is a relationship between knowledge about $R M$ and behavior towards implementing RM.

$H_{10}$ : There is a relationship between training in the field of $R M$ and behavior towards the implementation of RM.

$H_{11}$ : There is a relationship between the regulations on RM and the behavior towards the implementation of RM.

$H_{12}$ : There is a relationship between stakeholder requirements and behavior towards $R M$ implementation.

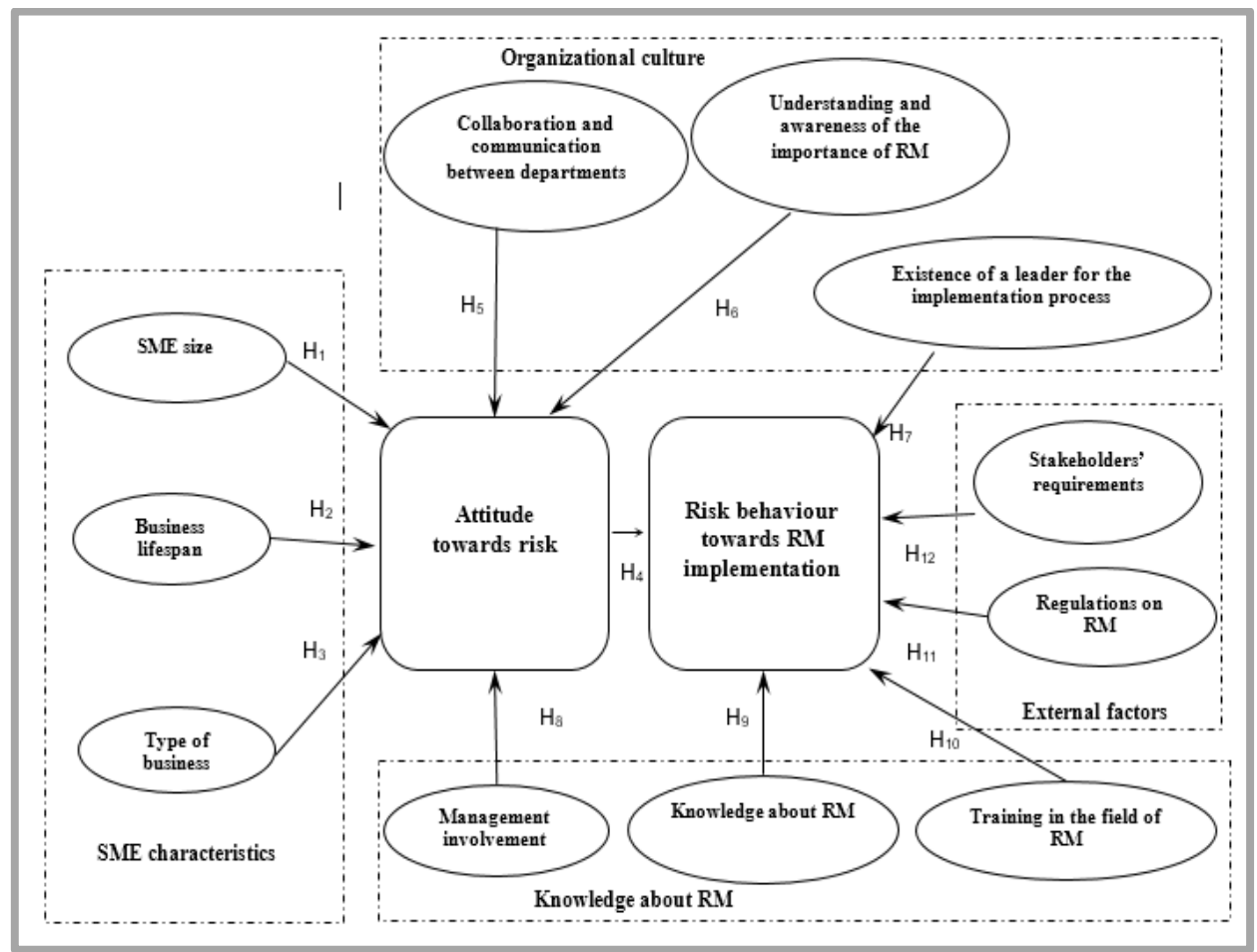

Figure no. 1. The model of determinants of behavior towards RM implementation

Source: authors' own conception 
The model has been fed with data obtained by conducting a survey based on a questionnaire to which 146 SMEs out of the 250 responded. The profile of the responding firms is presented in Table no. 2. Respondents were asked to give a score between 1 and 100 for each item in the questionnaire in order to assess the extent to which the statement in question is applicable to their organization. From the beginning we expected that the number of responding firms will be small, so we have established that for data analysis to use a fuzzy statistical analysis. The type of analysis is recommended both to eliminate the subjectivity of the responses and when the data set is reduced for a classical statistical analysis (Kim, Moskowitz and Koksalan, 1996).

Table no. 1. Determinants on RM implementation

\begin{tabular}{|c|c|}
\hline Determinant & Question \\
\hline \multicolumn{2}{|l|}{ SME characteristics } \\
\hline SME size & Possible values: Micro-enterprise; Small enterprise; Medium enterprise \\
\hline Business lifespan & $\begin{array}{l}\text { Possible values: less than } 1 \text { year; } 1-5 \text { years; } 5 \text { - } 10 \text { years; } 10-25 \text { years; } \\
\text { over } 25 \text { years }\end{array}$ \\
\hline Type of business & $\begin{array}{l}\text { Possible values: Trade, Construction, Consulting, Food industry, } \\
\text { Chemical industry, Manufacturing industry, Other }\end{array}$ \\
\hline \multicolumn{2}{|l|}{ Organizational culture } \\
\hline $\begin{array}{l}\text { Collaboration and } \\
\text { communication } \\
\text { between departments }\end{array}$ & $\begin{array}{l}\text { Evaluate on a scale from } 1 \text { to } 100 \text { the extent to which you consider that } \\
\text { promoting collaboration and communication between departments } \\
\text { contributes to changing the attitude towards risk. }\end{array}$ \\
\hline $\begin{array}{l}\text { Understanding and } \\
\text { awareness of the } \\
\text { importance of RM }\end{array}$ & $\begin{array}{l}\text { Evaluate on a scale from } 1 \text { to } 100 \text { the extent to which you consider that } \\
\text { understanding and awareness of the importance of RM contributes to } \\
\text { changing the attitude towards risk. }\end{array}$ \\
\hline $\begin{array}{l}\text { Existence of a leader } \\
\text { for the implementation } \\
\text { process }\end{array}$ & $\begin{array}{l}\text { Evaluate on a scale from } 1 \text { to } 100 \text { the extent to which you consider that } \\
\text { the existence of a leader for the implementation process influences the } \\
\text { decision to implement the RM. }\end{array}$ \\
\hline \multicolumn{2}{|l|}{ Knowledge about RM system } \\
\hline $\begin{array}{l}\text { Management } \\
\text { involvement }\end{array}$ & $\begin{array}{l}\text { Evaluate on a scale from } 1 \text { to } 100 \text { the extent to which the involvement } \\
\text { of the management in supporting the implementation process contributes } \\
\text { to changing the attitude towards risk. }\end{array}$ \\
\hline Knowledge about RM & $\begin{array}{l}\text { Evaluate on a scale from } 1 \text { to } 100 \text { the extent to which you appreciate that } \\
\text { knowledge about RM contributes to the implementation of RM. }\end{array}$ \\
\hline $\begin{array}{l}\text { Training in the field of } \\
\text { RM }\end{array}$ & $\begin{array}{l}\text { Evaluate on a scale from } 1 \text { to } 100 \text { the extent to which you consider that } \\
\text { the training of employees in the field of RM influences its } \\
\text { implementation. }\end{array}$ \\
\hline \multicolumn{2}{|l|}{ External factors } \\
\hline $\begin{array}{l}\text { Stakeholders' } \\
\text { requirements }\end{array}$ & $\begin{array}{l}\text { Evaluate on a scale from } 1 \text { to } 100 \text { the extent to which you appreciate that } \\
\text { stakeholders' requirements influence the implementation of RM in your } \\
\text { organization. }\end{array}$ \\
\hline Regulations on RM & $\begin{array}{l}\text { Evaluate on a scale of } 1 \text { to } 100 \text { the extent to which you consider that RM } \\
\text { regulations influence the implementation of RM in your organization. }\end{array}$ \\
\hline Attitude towards risk & $\begin{array}{l}\text { Evaluate on a scale from } 1 \text { to } 100 \text { the extent to which you consider that } \\
\text { the risk attitude contributes to the decision for RM implementation. }\end{array}$ \\
\hline $\begin{array}{l}\text { Behavior towards } \\
\text { implementation }\end{array}$ & $\begin{array}{l}\text { Evaluate on a scale from } 1 \text { to } 100 \text { the extent to which RM methods, tools } \\
\text { and practices are used in the organization. }\end{array}$ \\
\hline
\end{tabular}

Source: authors' conception

At the beginning of the questionnaire each respondent was asked to evaluate on a scale of 1 to 100 the linguistic variables: Very Low, Low, Medium, High, Very high (Table no. 3). 
Table no. 2. The profile of the responding firms

\begin{tabular}{|llcc|}
\hline Indicator & Possible values & Frequency & Percentage (\%) \\
\hline The size of SME & Micro-enterprise & 81 & 55.40 \\
& Small enterprise & 30 & 20.55 \\
& Medium enterprise & 35 & 23.97 \\
Business lifespan & Less than 1 year & 10 & 6.85 \\
& 1-5 years & 28 & 19.18 \\
& 5-10 years & 37 & 25.34 \\
& 10-25 years & 51 & 34.93 \\
Industry & Over 25 years & 20 & 13.70 \\
& Trade & 24 & 16.44 \\
& Construction & 9 & 6.16 \\
& Consulting & 53 & 36.30 \\
& Food industry & 8 & 5.48 \\
& Chemical industry & 6 & 4.11 \\
& Manufacturing Industry & 26 & 17.81 \\
& Other & 20 & 13.70 \\
\hline
\end{tabular}

Source: authors' processing based on information from questionnaire responses

Table no. 3. The scale of linguistic variables

\begin{tabular}{|cccccc|}
\cline { 2 - 6 } \multicolumn{1}{c|}{} & \multicolumn{5}{c|}{ The scale of linguistic variables (0-100) } \\
\hline Respondent & $\begin{array}{c}\text { VL } \\
\text { (Very Low) }\end{array}$ & $\begin{array}{c}\text { L } \\
\text { (Low) }\end{array}$ & $\begin{array}{c}\text { M } \\
\text { (Medium) }\end{array}$ & $\begin{array}{c}\text { H } \\
\text { (High) }\end{array}$ & $\begin{array}{c}\text { VH } \\
\text { (Very High) }\end{array}$ \\
\hline 1 & $0-5$ & $5-25$ & $25-75$ & $75-95$ & $95-100$ \\
2 & $0-10$ & $10-30$ & $30-70$ & $70-90$ & $90-100$ \\
3 & $0-15$ & $15-35$ & $35-65$ & $65-85$ & $85-100$ \\
$\ldots \ldots \ldots$ & $\ldots \ldots \ldots$. & $\ldots \ldots \ldots$. & $\ldots \ldots \ldots$. & $\ldots \ldots \ldots \ldots$ & $\ldots \ldots \ldots \ldots$. \\
146 & $0-10$ & $10-25$ & $25-75$ & $75-90$ & $90-100$ \\
\hline
\end{tabular}

Source: authors' processing based on information from questionnaire responses

The given answers were used to represent the linguistic variables through histograms (Figure no. 2). The shape of the histograms determined the type of fuzzy functions used. For the linguistic variables Very Low and Very High were used trapezoidal fuzzy functions, for the other linguistic variables were used triangular fuzzy functions (Table no. 4).
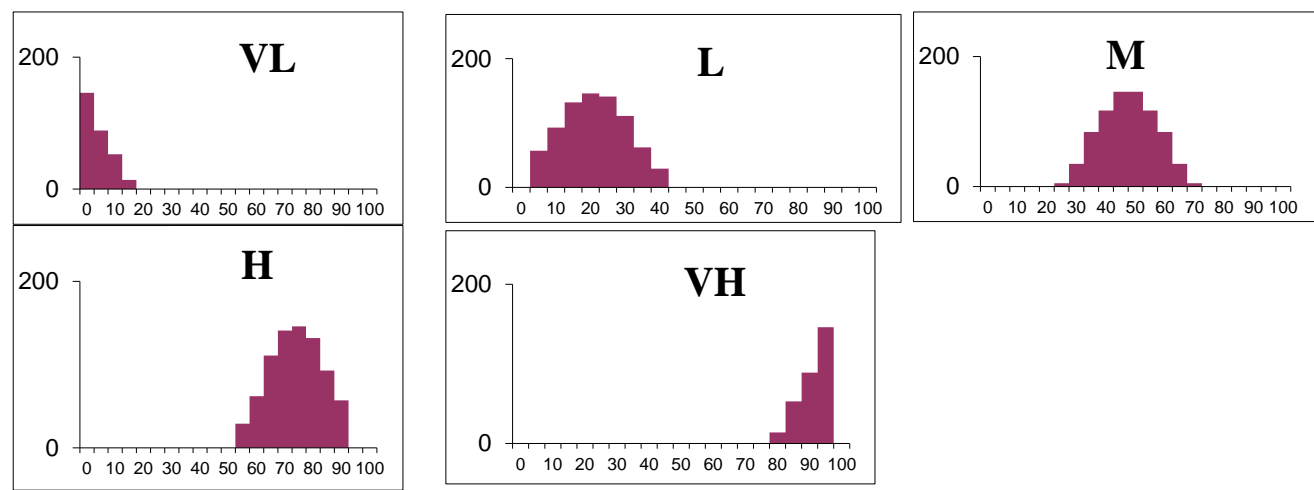

Figure no. 2. Histograms associated to linguistic variables 
Table no. 4. Fuzzy numbers for linguistic terms

\begin{tabular}{|cc|}
\hline Linguistic term & FN \\
\hline VL & $(0,0,5,20)$ \\
L & $(5,20,45)$ \\
M & $(25,50,75)$ \\
H & $(55,80,95)$ \\
VH & $(80,95,100,100)$ \\
\hline
\end{tabular}

Source: authors' processing based on information from questionnaire responses

Figure no. 3 shows the graphical representation of the membership functions of the linguistic variables.

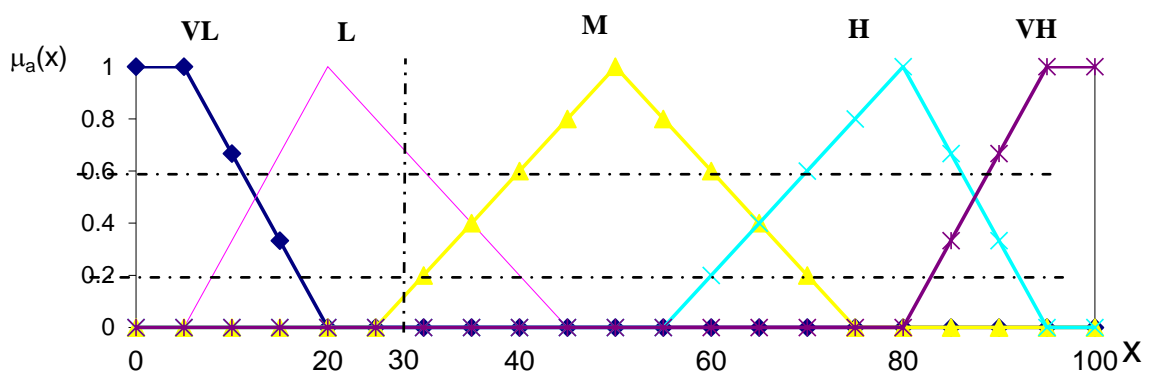

Figure no. 3. The membership functions of linguistic variables

Source: authors' processing based on information from questionnaire responses

The next step was the fuzzification of the answers given by each respondent. Each analyzed aspect was evaluated by each respondent on a scale of 1 to 100 . The fuzzy number $\mu\left(R_{i j}\right)$ attached to each response was calculated with relation (1).

$\mu\left(R_{i j}\right)=\frac{\mu_{V L}\left(R_{i j}\right)}{V L} \oplus \frac{\mu_{L}\left(R_{i j}\right)}{L} \oplus \frac{\mu_{M}\left(R_{i j}\right)}{M} \oplus \frac{\mu_{H}\left(R_{i j}\right)}{H} \oplus \frac{\mu_{V H}\left(R_{i j}\right)}{V H}$

where $R_{i j}$ represents the response given by respondent $\mathrm{i}$ to question $\mathrm{j}$.

The degree of membership $\mu(x)$ is calculated determining the point of intersection between the function of the linguistic variable and the vertical line passing through the point $\mathrm{x}$. In Figure no. 3 is exemplified the calculation method for the value $\mathrm{x}=30 \quad\left(\mu_{V L}(30)=0\right.$; $\left.\mu_{L}(30)=0.6 ; \mu_{M}(30)=0.2 ; \mu_{H}(30)=0 ; \mu_{V H}(30)=0 ;\right)$.

For hypotheses testing we used the $\chi 2$ fuzzy test (Nguyen and $\mathrm{Wu}, 2006$ ). The difference from the classical statistical method appears when constructing the contingency table because a value can have at the same time partial membership in several groups. If there are two fuzzy groups $G=\left\{\tilde{G}_{1}, \ldots, \tilde{G}_{t}\right\}$ and $H=\left\{\tilde{H}_{1}, \ldots, \tilde{H}_{k}\right\}$ (t the number of groups in the independent variable and $\mathrm{k}$ the number of groups in the dependent variable, $\mathrm{n}$ the total number of observations), the frequency of occurrence $f_{i j}$ is calculated with the formula (2) (Taheri, et al., 2016; Georgescu, 2002; Colesca, et al., 2017).

$f_{i j}=\sum_{k=1}^{n} \min \left(\mu_{G_{i}}\left(\tilde{x}_{k}\right), \mu_{H_{j}}\left(\tilde{y}_{k}\right)\right)$ 
For example, if two values $\mathrm{x}_{1}=30$ and $\mathrm{y}_{1}=40$ are fuzzified:

$$
\begin{aligned}
& \mu(30)=\frac{0}{V L} \oplus \frac{0.6}{L} \oplus \frac{0.2}{M} \oplus \frac{0}{H} \oplus \frac{0}{V H} \\
& \mu(40)=\frac{0}{V L} \oplus \frac{0.2}{L} \oplus \frac{0.6}{M} \oplus \frac{0}{H} \oplus \frac{0}{V H} \\
& \min _{L-L}(\mu(30), \mu(40))=\min (0.6,0.2)=0.2 ; \min _{L-M}(\mu(30), \mu(40))=\min (0.6,0.6)=0.6
\end{aligned}
$$

Depending on the tested hypothesis we have 2 types of contingency tables. Figure no. 4 shows the contingency table when only one variable is fuzzy. Figure no. 5 shows the contingency when both variables are fuzzy.

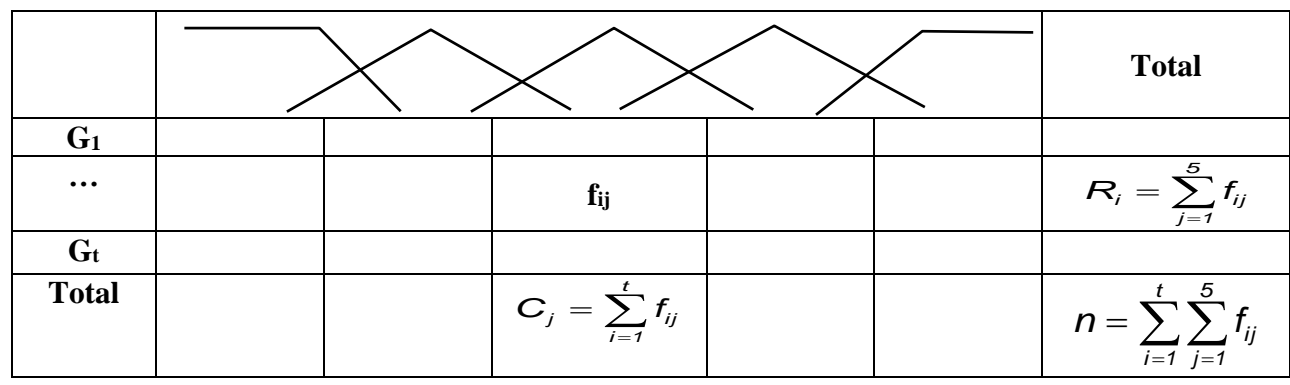

Figure no. 4: The contingency table for hypotheses H1, H2, H3

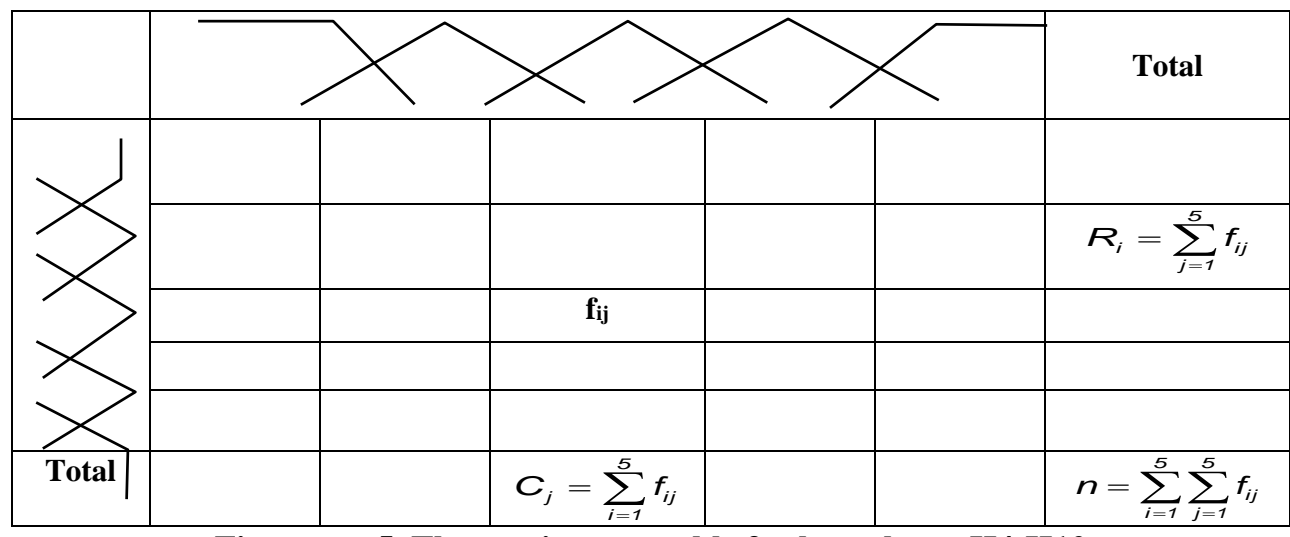

Figure no. 5. The contingency table for hypotheses H4-H12

For each hypothesis was defined the null hypothesis $\mathrm{H}_{0}$ : "The analyzed variables are statistically independent (there is no association between the analyzed variables)" and the alternative hypothesis $\mathrm{H}_{\mathrm{a}}$ : "There is an association between the analyzed variables".

The value $\chi^{2}$ (Nguyen and $\mathrm{Wu}, 2006$ ) is calculates using relation (3).

$$
\mathcal{X}^{2}=\sum_{i \in G} \sum_{j \in H} \frac{\left(f_{i j}-E_{i j}\right)^{2}}{E_{i j}}, \quad E_{i j}=\frac{R_{i} * C_{j}}{n},
$$

If $\mathrm{p}\left(\chi^{2}\right) \leq \alpha$, where $\alpha$ is the significance level, then $\mathrm{H}_{0}$ is rejected. 


\section{Results and discussions}

The study aimed to identify the determinants of the behavior towards RM implementation in Romanian SMEs. By conducting a questionnaire-based survey, 12 research hypotheses were tested. The answers to the questions outlined a global picture over the way in which the Romanian SMEs are prepared to respond to the challenges of an increasingly turbulent business environment. The results of the hypothesis testing are presented in Table no. 5. The calculations were performed using the Microsoft Excel.

Table no. 5. The results of hypotheses testing

\begin{tabular}{|cccc|}
\hline Hypothesis & $\boldsymbol{\chi}^{2}$ & $\boldsymbol{p}$ & $\begin{array}{c}\text { Acceptation of the null hypothesis } \\
\text { YES (there is no connection between the analyzed variables) / } \\
\text { NO (there is a connection between the analyzed variables) }\end{array}$ \\
\hline $\mathrm{H}_{1}$ & 11.22 & 0.190 & YES \\
$\mathrm{H}_{2}$ & 28.53 & 0.027 & NO \\
$\mathrm{H}_{3}$ & 30.42 & 0.171 & YES \\
$\mathrm{H}_{4}$ & 41.21 & 0.001 & NO \\
$\mathrm{H}_{5}$ & 13.52 & 0.634 & YES \\
$\mathrm{H}_{6}$ & 27.62 & 0.035 & NO \\
$\mathrm{H}_{7}$ & 31.24 & 0.013 & NO \\
$\mathrm{H}_{8}$ & 12.38 & 0.717 & YES \\
$\mathrm{H}_{9}$ & 29.51 & 0.021 & NO \\
$\mathrm{H}_{10}$ & 27.09 & 0.040 & NO \\
$\mathrm{H}_{11}$ & 15.73 & 0.472 & YES \\
$\mathrm{H}_{12}$ & 32.48 & 0.009 & NO \\
\hline
\end{tabular}

Source: processing by the authors based on information resulting from the Microsoft Excel

Two basic categories of factors were analyzed in the development of the RM implementation model. The first category, represented by attitude towards risk, shows the natural inclination of stakeholders or organizations to the extent that they are willing to take the risk and is based on the perception of a specific situation (Hillson and Murray-Webster, 2006). Risk attitude exist at individual, group, corporate and national level and can be evaluated and described with a degree of accuracy. The type of attitude towards risk (prudent, risky or neutral) exerts its influence on the RM process, a clearly defined attitude towards risk contributing to a proactive behavior towards the implementation of RM. The research focuses on the level of the attitude of the employees towards the RM, which in turn influences the behavior towards the implementation of RM. A favorable attitude of the employees towards the implementation of any type of system can promote the constructive involvement in the implementation process and, subsequently, it can lead to the enthusiastic adoption of its results (Chaudhry, 2018). On the other hand, the behavior towards the implementation of RM is influenced by the actions taken both by individuals and the organization. This is visible in the RM practices, methods and tools that the respondents indicated that they use in the daily work. It is generally accepted that a well-defined risk attitude contributes to a behavior supporting RM implementation. Hillson and Murray-Webster (2006) highlight that the attitude of individuals and organizations has a significant influence on the extent to which RM offers what it promises. The link between attitude and behavior towards the implementation of RM is validated within the model by hypothesis $\mathrm{H}_{4}$, and the relationship between variables is statistically significant.

Hypotheses concerning "SME characteristics". The obtained results indicate that there is no connection between SME size and its attitude towards risk. The fact that the most of the 
SMEs answered that they are microenterprises is an explanation of this result. Microenterprises face many risks, but the size of the organizations does not allow the hiring of resources for the implementation of a RM system. According to expectations, the research indicates that business lifespan has a relevant influence on the attitude towards risk. SMEs that are in business for a long time have a better defined attitude to risk. This may be due to the fact that they have had the opportunity to test the effect of some RM practices on their activity and realized that these practices could have a significant positive impact on a long term. The type of business does not significantly influence the risk attitude of Romanian SMEs. This result may be influenced by the fact that most of the SME's included in the sample are consulting firms, the next two positions being occupied by trade and the manufacturing firms. The result is similar to that obtained by Yaraghi and Langhe (2011) who found that the influence of the type of business on the intention to implement RM is outweighed by many other factors such as: an well-defined strategy (which includes the involvement of top management and education), team spirit (leadership, communication, team-building and consultants) and the responsibility assumed.

Hypotheses concerning "Organizational culture”. Opposite to most studies that identify the existence of a significant correlation between both collaboration and communication between departments and the level of management involvement on the implementation of RM, the present study doesn't prove statistically significant correlations (hypotheses $\mathrm{H}_{5}$, respectively $\mathrm{H}_{8}$ ). Understanding and awareness of the importance of $\mathrm{RM}$, as a component of the organizational culture, influences the attitude towards the implementation of RM. The existence of a leader who leads the implementation process is one of the factors that appear most frequently mentioned in previous studies (Dornberger, Oberlehner and Zadrazil, 2014; Fraser and Simkins, 2016) and also appears to be relevant in the decision of implementation of RM in Romanian SMEs. The fact that two of the factors in the organizational culture group act in favor of RM implementation supports the idea of Hillson and Murray-Webster (2006) who state that the most critical success factor for effective RM is an adequate and mature risk culture.

Hypotheses concerning "Knowledge about RM". The behavior towards the implementation is influenced by the employees RM knowledge, but also by the extent to which trainings in the field are organized. The results are in line with those obtained by Yaraghi and Langhe (2011) and Dornberger, Oberlehner and Zadrazil (2014).

Hypotheses concerning "External factors". Although Ciocoiu (2015) showed that in the Romanian context the regulations on RM were among the factors with relevant influence on the implementation, the current research no longer confirms this aspect $\left(\mathrm{H}_{11}\right)$. One of the explanations is based on the fact that the highest share of surveyed organizations are microenterprises that are not obliged by legislative regulation to implement such a system. Stakeholder requirements have always been a factor that SMEs are sensitive to, whether they are customers, stockholders or business partners. The study shows that there is a link between the stakeholders' requirements and the behavior towards the RM implementation, proving that the pressure from them leads to the initiation of some actions of the RM (Ciocoiu, 2015).

\section{Conclusions}

The present study makes a significant contribution to the advancement of research on the factors influencing the implementation of RM in Romanian SMEs, a still unexplored topic. 
The results showed that the requirements of stakeholders, the existence of a leader to lead the implementation process, the knowledge and training in the field, are important determinants of SMEs behavior towards the implementation of RM systems. The attitude towards the implementation of RM is less influenced by the characteristics of SMEs, the only statistically significant determinant being the "business lifespan". Another important determinant of attitude is the "understanding and awareness of the importance of RM", respectively, the extent to which it provides the expected results. "Regulations on RM" do not influence behavior towards implementation, although a study conducted a few years ago revealed that it could be a factor driving implementation.

From a practical point of view, the results of the present study are of interest to any type of organization that implements an integrated approach of RM, as it provides knowledge about understanding the factors that may influence such a process. The study helps Romanian SMEs to improve their risk management processes and, therefore, to compete in difficult business environments and to take better advantage of opportunities.

Regarding the limits of the research, they consist in the fact that the number of SMEs that responded to the questionnaire is relatively small, and the largest share is held by microenterprises. The next steps of the research will be focused on the growth of number of respondents, the inclusion in the analysis of a larger number of factors, as well on the analysis of correlations between them. However, the purpose of this study was to make analytical generalizations using a theoretical framework, in order to put the foundations of a logic that might be applicable in other situations, but not for statistical generalization. The identified factors could be used in the future as a useful "roadmap" for the successful implementation of RM in Romanian SMEs.

The research aimed to identify the relevant factors that influence the implementation of RM in Romanian SMEs. The inclusion of SMEs in the sample is based on the fact they have a large share and importance in the national economy. In the same time, these organizations have limited resources to support such a management system. The data were collected through a questionnaire, and the hypothesis testing was performed using the fuzzy approach, to eliminate the shortcoming caused by the relatively small number of responses. A novelty element of the model is represented by the fact that in the analysis of the determinants of the implementation of RM is introduced the risk attitude which, in turn, influences the behavior towards the implementation. The study, also, has a contribution in the research concerning the evaluation of challenges of sustainable development of Romanian organizations.

\section{Acknowledgement}

This study is conducted within the Management Ph.D. School of the Bucharest University of Economic Studies.

\section{References}

Agrawal, R., 2016. Enterprise RM' essential for survival and sustainable development of micro, small and medium enterprises. International Review, 1-2, pp. 117-124. DOI: $10.5937 /$ intrev1602117A 
Agyakwa-Baah, A. and Chileshen, N., 2010. Critical success factors for risk assessment and management practices (RAMP) implementation within the Ghanaian construction organisations, In: Wang, Y., Yang, J., Shen, G.Q.P., and Wong, J., Eds. Proceedings of the 8th International Conference on Construction and Real Estates Management (ICCREM 2010). Leading Sustainable Development through Construction and Real Estates Management, Beijing. 1-3 December 2010, pp. 345-352. DOI: 10.13140/RG.2.1.2995.3766

Beasley, M.S., Clune, R., and Hermanson, D.R., 2005. Enterprise Risk Management: An empirical analysis of factors associated with the extent of implementation. Journal of Accounting and Public Policy, 24(6), pp.521-531.

Brătianu, C., 2015. Developing strategic thinking in business education. Management dynamics in the knowledge economy, [online] Available at: <http://www.managementdynamics.ro/index.php/journal/article/view/144/89> [Accessed 05 June 2020].

Chaudhry, S., 2018. Managing employee attitude for a successful information system implementation: a change management perspective. Journal of International Technology and Information Management, 27(1), pp.58-90.

Ciocoiu, C.N., 2015. Implementation of an integrated risk management framework: a multicriteria approach for Romanian SMEs. In: Nicolescu, O., Oprean, C. and Titu, M.A., Eds: The Best Romanian Management Studies 2013-2014, Lambert Academic Publishing.

Colesca, S.E., Pacesila, M., Burcea, S.G., Ciocoiu, C.N. and Bugheanu, A.M., 2017. Analysis of passenger's satisfaction with the quality of the public transportation mode choices in Bucharest: A fuzzy approach. Economic Computation and Economic Cybernetics Studies and Research, 51(4), pp. 109-125.

COSO, 2004. Enterprise risk management-integrated framework: Application techniques. [pdf] Committee of Sponsoring Organizations of the Treadway Commission. Available at: <https://www.coso.org/documents/Framework\%20Reference\%20Secured.pdf> [Accessed 05 June 2020].

Dornberger, K., Oberlehner, S. and Zadrazil, N., 2014. Challenges in implementing enterprise risk management. ACRN Journal of Finance and Risk Perspectives, 3(3), pp.1-14.

EIU, 2007. Best practice in risk management: A function comes of age. [pdf] A report from the Economist Intelligence Unit sponsored by ACE, IBM and KPMG. Available at: <http://graphics.eiu.com/files/ad_pdfs/eiu_Risk_Management.pdf> [Accessed 10 March 2020].

Fedorov, G.M. and Mikhaylov, A.S., 2019. Socioeconomic asymmetry in regional development across Russia. Theoretical and Empirical Researches in Urban Management, 14(4), pp.35-52.

Fraser, J.R.S. and Simkins, B.J., 2016. The challenges of and solutions for implementing enterprise RM. Business Horizons, 59(6), pp.689-698.

Gates, S., 2006. Incorporating strategic risk into enterprise risk management: A survey of current corporate practice. Journal of Applied Corporate Finance, 18(4), pp.81-90.

Georgescu, V., 2002. Chi-squared-based vs entropy-based mechanisms for building fuzzy discretizes, inducers and classifiers. Fuzzy Economic Review, 7(1), pp.3-27. 
Hillson, D. and Murray-Webster, R., 2006. Managing risk attitude using emotional literacy. [pdf] Project Management Institute. Available at: <http://citeseerx.ist.psu.edu/viewdoc/ download?doi=10.1.1.612.6869\&rep=rep1\&type=pdf $>$ [Accessed 05 June 2020].

Hoyt, R.E. and Liebenberg, A.P., 2011. The value of enterprise risk management. Journal of Risk Insurance, 78(4), pp.795-822. https://doi.org/10.1111/j.1539-6975.2011.01413.x.

Institution of Civil Engineers and the Faculty and Institute of Actuaries, 2009. ERM - a guide to implementation (Draft). [pdf] Institution of Civil Engineers and the Faculty and Institute of Actuaries: London. Available at: <https://www.actuaries.org.uk/ system/files/documents/pdf/ERMGuideJuly09.pdf> Accessed [15 March 2020].

ISO, 2018. ISO 31000:2018 Risk management - Principles and guidelines, [online] International Organization for Standardization. Available at: <https://www.iso.org/ standard/65694.html> [Accessed 5 March 2020].

Kleffner, A.E., Lee, R.B. and McGannon, B., 2003. The effect of corporate governance on the use of enterprise risk management: Evidence from Canada. Risk Management and Insurance Review, 6(1), pp.53-73.

Kim, K.J., Moskowitz, H. and Koksalan, M., 1996. Fuzzy versus statistical linear regression. European Journal of Operational Research, 92(2), pp.417-434.

Marinescu, P., Constantin, I. and Toma, S.G., 2016. Creativity, innovation and the perspectives of management. Management and Economics Review, 1(2), pp.71-81.

Mazlina, M. and Amirah, A., 2015. A case study of enterprise risk management implementation in Malaysian construction companies. International Journal of Economics and Financial Issues, 5(1S), pp.70-76.

Mikhaylova, A.A., Mikhaylov, A.S., Savchina, O.V. and Plotnikova, A.P., 2019. Innovation landscape of the Baltic region. Administraţie și Management Public, 33, pp.165-180.

Mudiyanselage, P. and Jayathilake, B., 2012. Risk management practices in small and medium enterprises: Evidence from Sri Lanka. International Journal of Multidisciplinary Research, 2(7), pp.226-234.

Nguyen, H.T. and Wu, B., 2006. Fundamentals of statistics with fuzzy data. Heidelberg: Springer -Verlag Berlin.

Ntlhane, K.E., 1995. The application of risk management principles to smaller enterprises. Johannesburg: University of the Witwatersrand.

Retkoceri, B. and Kurteshi R., 2019. Understanding the current status of innovation management practices in Kosovo firms. Management Research and Practice, 11(1), pp.43-55.

Rostami, A., Sommerville, J., Wong, I. and Lee, C., 2015. Risk management implementation in small and medium enterprises in the UK construction industry. Engineering, Construction and Architectural Management, 22(1), pp.91-107.

Taheri, S.M., Hesamian, G. and Viertl, R., 2016. Contingency tables with fuzzy information. Communications in Statistics - Theory and Methods, 45(20), pp.5906-5917. DOI: 10.1080/03610926.2014.953688.

UNEP Finance Initiative, 2006. Sustainability management and reporting: Benefits for financial institutions in developing and emerging economies. [pdf] Available at: <http://www.unepfi.org/fileadmin/documents/smr_benefits_dec2006_01.pdf.> [Accessed 23 February 2020]. 
Vadiveloo, J., Aguirre, M., Atlas, S.A., Bansal, A., Bird, R.C., Hussein, M.E., Park, S.K., Parsa, H.G., Ramsay, F. and Whitman, A., 2015. Enterprise risk management for small and medium-sized enterprises - First Edition. Schaumburg, IL: Society of Actuaries.

Vasile, E. and Croitoru, I., 2012. Integrated risk management system - Key factor of the management system of the organization, [online] Available at: <https://www.intechopen.com/books/risk-management-current-issues-and-

challenges/integrated-risk-management-system-key-factor-of-the-management-systemof-the-organization> [Accessed 23 February 2020].

Verbano, C. and Venturini, K., 2013. Managing risks in SMEs: A literature review and research agenda. Journal of Technology Management \& Innovation, 8(3), pp.186-197. DOI: $10.4067 /$ S0718-27242013000400017.

WBCSD, 2016. Sustainability and enterprise risk management: The first step towards integration. Geneva: World Business Council for Sustainable Development.

Yaraghi, N. and Langhe, R.G., 2011. Critical success factors for risk management systems. Journal of Risk Research, 14(5), pp.551-581.

Yilmaz, A.K. and Flouris, T., 2010. Managing corporate sustainability: risk management process based perspective. African Journal of Business Management, 4(2), pp.162-171.

Zhao, X. and Singhaputtangkul, N., 2016. Effects of firm characteristics on enterprise risk management: case study of Chinese construction firms operating in Singapore. Journal of Management in Engineering, 32(4), pp.1-9. 